\title{
Biopic, memoria y nostalgia: la biografía del criminal
}

\author{
El Angel | Luis Ortega | 2018 \\ Alfredo Dillon \\ Universidad Católica Argentina
}

Recibido 12 de junio de 2020; aprobado 25 de julio de 2020

\begin{abstract}
Resumen
El artículo propone pensar el género biopic en relación con la historia, la memoria y la nostalgia, a partir del caso de la película argentina El ángel (Luis Ortega, 2018), basada en la vida del asesino serial Carlos Robledo Puch y sus crímenes a comienzos de la década de 1970. El film se desliza desde el relato biográfico hacia un plano más amplio: el de la reflexión -en clave pop- sobre el mal. La biografía de Robledo Puch es una excusa para narrar una historia que rodea el problema del mal y la libertad, la belleza y la perversión, la violencia y el erotismo como contracaras de la vida "normal", de la existencia gris de las mayorías sociales que permanecen anónimas. A partir de una mirada nostálgica sobre los años 70, la biopic toma el nombre propio de Robledo Puch y algunas circunstancias históricas para darle identidad a una figura formada, sobre todo, de la sustancia de lo mítico.
\end{abstract}

Palabras Clave: Cine argentino | Cine biográfico | Biopic | Memoria | Nostalgia

Biopic, memory and nostalgia: a criminal's biography

Abstract

The article reflects on the biopic genre in relation to history, memory and nostalgia, based on the case of the Argentine film El Ángel (Luis Ortega, 2018), based on the life of serial killer Carlos Robledo Puch and his crimes in the early 1970s. The film slides from the biographical account to a broader scope: that of reflection -in a pop style- about evil. The biography of Robledo Puch works as an excuse to tell a story that deals with the problems of evil and freedom, beauty and perversion, violence and eroticism, as the reverse of the "normal" life, the gray existence of the social majorities that remain anonymous. With a nostalgic approach to the 70's, Ortega's biopic uses Robledo's name and some historical circumstances to give identity to a character with a mythical essence.

Keywords: Argentine cinema | Biographical cinema | Biopic | Memory | Nostalgia

\section{Introducción}

Monstruo, sádico, asesino, diablo, chacal, ángel negro. La enumeración de calificativos con que la prensa de la época se refirió a Carlos Robledo Puch sintetiza la dimensión que adquirió su figura en la imaginación pública y la memoria colectiva: es probablemente el asesino más célebre de la Argentina. Paradójicamente, esa dimensión excepcional de la figura de Robledo Puch hace que El ángel (Luis Ortega, 2018), la biopic basada en su vida, se deslice desde el relato biográfico hacia un plano más amplio: el de la reflexión -en clave pop y pastiche- sobre el problema del mal. El guion del film estuvo a cargo del propio Ortega junto con el periodista Rodolfo Palacios -autor de la biografía El ángel negro-y el escritor Sergio Olguín. La producción estuvo a cargo de El Deseo, Kramer \& Sigman, Telefe y Underground, además del apoyo del INCAA.
La película fue un éxito de taquilla: logró el récord en cantidad de salas para un estreno argentino, con 352 pantallas (Cines Argentinos, 2018), y superó el millón de espectadores, convirtiéndose en la película argentina más vista del año. Además, fue la precandidata argentina al premio Oscar 2019 a Mejor Película Extranjera y al premio Goya a Mejor Película Iberoamericana.

En apenas unos meses (entre el 15 de marzo de 1971 y el 3 de febrero de 1972), Robledo Puch mató a balazos a 11 personas "por la espalda o mientras dormían" ( $\mathrm{Pa}-$ lacios, 2018, p. 20). En ese momento, el asesino tenía 19 años, y se ganó el apodo que da título a la película por el contraste entre su apariencia física -joven, rubio, belloy sus acciones criminales. En 1980 fue condenado por los 11 homicidios, una tentativa de homicidio, 16 robos, una violación, dos raptos y abuso, entre otros delitos. Desde entonces está en la cárcel: además de ser uno de los principales asesinos seriales de la historia argentina,

*alfredodillon@yahoo.com 
es también el preso más antiguo del sistema penitenciario -en 2018, año de estreno de la película, había cumplido 46 años de reclusión-.

La fama inmediata de Robledo Puch empezó a edificarse en la prensa de la época. Una de las figuras que contribuyó a esa construcción fue el escritor y periodista Osvaldo Soriano. En un célebre artículo publicado en febrero de 1972 en La Opinión, Soriano sintetiza el impacto de los hechos protagonizados por Robledo Puch:

Nunca un caso policial conmovió tanto a la sociedad argentina. Durante varios días toda la actividad política, deportiva, artística pasó a segundo plano ante una evidencia: en Buenos Aires, un muchacho puede por sí solo quebrar todas las barreras de seguridad, matar y robar sin que la justicia lo alcance hasta que la tragedia haya abrazado a muchos. [...] Muchos han querido cuestionar, a través de Robledo Puch, a toda una sociedad. Otros piensan que se trata de un caso aislado, de un hombre desesperado. (Cit. en Palacios, 2018, p. 11)

Ese impacto perduraría en la memoria colectiva a través del tiempo: Robledo Puch se convirtió en una suerte de arquetipo nacional del asesino serial, una versión criolla de Charles Manson, según él mismo se ha definido. El de Ortega no fue el primer intento de llevar la historia de Robledo al cine: en 1987, los cineastas Juan Carlos Desanzo y Eduardo Mignogna visitaron al asesino en la cárcel e intentaron obtener los derechos para hacer una película sobre su vida, pero no llegaron a un acuerdo. También José Pablo Feinmann escribió un guion que finalmente no se filmó. Y el ciclo televisivo Sin condena (1995), dirigido por Rodolfo Ledo, incluyó un capítulo sobre el “Ángel negro”.

\section{Biopic y memoria}

La biopic constituye un género específico dentro del cine biográfico: las biopics son películas de ficción que dramatizan una porción de la historia de vida de una o varias personas cuya existencia real está acreditada. Dentro del cine biográfico incluimos documentales centrados en biografías (de personajes históricos, artistas, deportistas, criminales, etcétera); la biopic, en cambio, se presenta como un film de ficción basado en hechos reales. Podemos pensar la biopic como una ficción híbrida, de igual manera que los documentales biográficos muchas veces incorporan ficcionalizaciones. En este trabajo preferimos el término biopic antes que biofilm (Rosenstone, 2006) porque el segundo abarca también películas documentales, mientras que nuestro objeto de análisis serán las ficciones biográficas.
El interés contemporáneo en la biopic se inscribe en un contexto más amplio: la biografía en sus diversas formas y enfoques ha ocupado el centro de la escena en los debates de la teoría literaria, la historia, los estudios culturales y las ciencias sociales. Este movimiento ha sido categorizado como un "giro subjetivo" (Sarlo, 2005) o "giro biográfico" (Arfuch, 2002). Estos procesos son correlativos del boom que experimentaron en los últimos veinte años el testimonio, la autobiografía, la crónica y otros géneros del yo. En el campo cinematográfico, ese boom contribuye a explicar el interés en el género biográfico, pero también se expresó en un auge del documental -en particular, del documental en primera persona- y en la proliferación global de "nuevos realismos" -desde el brasileño Fernando Meirelles hasta el iraní Abbas Kiarostami-.

Aunque durante décadas ha predominado la desconfianza de los historiadores con respecto al cine, los aportes de autores como Marc Ferro, Pierre Sorlin y Robert Rosenstone contribuyeron a acercar posiciones entre cine e historia. Desde esta perspectiva, ciertas reflexiones han puesto el foco en las particularidades que adquiere la biografía en el discurso audiovisual y en el discurso verbal. Rosenstone, por ejemplo, compara las biografías literarias y las biografías cinematográficas, y destaca en estas últimas dos cualidades, la capacidad de producir identificación y la vividez que supone la narración cinematográfica, desplegada siempre en presente:

\section{El cine puede carecer de la capacidad de proporcionar una visión psicológica profunda, o descripciones extensas de contextos intelectuales o políticos particulares, pero puede sugerir con una inmediatez impresionante cómo se veía el pasado y cómo la gente se movía, sentía, hablaba y actuaba en otras épocas. A diferencia de la palabra escrita, el bio- film, incluso en sus flashbacks, funciona siempre en tiem- po presente, $y$ hasta te hace sentir como si hubieras vivido esos momentos vos mismo. (2006, p. 108)}

Por su parte, Moulin (2016) estudia el impacto de la biopic -él prefiere hablar de biofilm o, siguiendo a $\mathrm{Ha}$ yden White, biophoty- en los estudios biográficos. Para este autor, la biografía cinematográfica ha contribuido a un "efecto de condensación” en las narrativas biográficas en general. Mientras la biografía tradicional se autoimponía el mandato de narrar una vida "desde el nacimiento hasta la tumba", la biopic-cuya duración promedio no suele exceder las dos horas- siempre recorta los acontecimientos más significativos o el período más relevante en la vida del personaje, en función del punto de vista que se quiere plantear sobre él/ella: "Este aspecto característico de la biofotía (biophoty) ejerce una influencia 
muy interesante en la biografía moderna, liberándola de la obligación largamente autoimpuesta de contar una vida desde la cuna hasta la tumba" ${ }^{3}$.

En esta línea, autores como Renders proponen denominar "biografías parciales" (2017, p. 91) a aquellas narraciones que renuncian a abarcar toda la cronología de una vida: es el caso, por ejemplo, de todas las biopics que analizamos en este libro. De todos modos, el concepto de biografía parcial constituye una redundancia: toda biografía, incluso la que sigue al protagonista desde el nacimiento hasta la muerte, implica un recorte. Por su misma condición de representación, toda biografía es parcial; la narración (biográfica) no puede confundirse con su objeto (una vida) ni tampoco "reflejarlo". En ese sentido, la biopic no hace más que poner en evidencia los procedimientos de selección, condensación, conexión y elipsis -en una palabra, lo que White (1992) denomina "entramado" - que cualquier narrativa biográfica, incluso la más "científica”, pone en juego.

El éxito de tantas biopics recientes, su buen desempeño en términos de público, ha obturado en ciertos casos la consideración de un aspecto fundamental del género: su incidencia en la construcción de la memoria colectiva. Entendemos la memoria como un conjunto de representaciones sobre el pasado construidas desde el presente: esas representaciones son provisorias y cambiantes, y se inscriben en disputas sobre los sentidos del pasado. Pese a que el estudio pionero de Custen (1992) ya ponía el acento en la función "cívica" del cine biográfico y su relevancia en la construcción pública de la historia, recién en los últimos 15 años han empezado a aparecer aproximaciones que vinculan biopic y memoria.

Robinson caracteriza el género biopic a partir de su intención persuasiva: estas narraciones se presentan como "historias verdaderas"; intentan convencer al espectador de que las cosas "sucedieron así". "La mayoría de las biopics emplean estrategias y técnicas convencionales para persuadir a la audiencia de que la representación es 'factual'" (2016, p. 7) $)^{5}$. Entre estas estrategias de persuasión, la consigna "basado en hechos reales" -repetida en afiches, trailers, créditos y leyendas que abren o cierran los films- es una de las utilizadas con mayor frecuencia, tanto al interior de la construcción narrativa como en la campaña comercial de promoción de estos films.

En la biopic, el presente narrativo se presenta como pasado histórico. A la vez, ese pasado (diegético) es moldeado por el presente (de la enunciación). La idea de que la memoria del pasado se ve determinada por el presente ya estaba en los trabajos de Halbawchs, teórico pionero de los estudios sobre memoria social. Como explica Lavabre, la teoría del sociólogo francés postulaba que "el pasado no se conserva; se reconstruye a partir del presente" y que "el pasado, mitificado, solo es convocado para justificar representaciones sociales presentes" (2007, p. 8). Esta sería la función social de la memoria, regida siempre por el presente $y$, por lo tanto, atada a sus vaivenes.

\section{Recortes, omisiones, invenciones}

El ángel es la primera película de Luis Ortega basada -más precisamente: inspirada-en una historia real. Sin embargo, aquí la biografía de Robledo Puch funciona más como una herramienta de marketing -permite que el público "reconozca" rápidamente al film a partir de su conexión con la memoria colectiva- que como hipotexto (Genette, 1989) para la construcción de la trama. En este sentido, El ángel constituye una reflexión sobre el mal como una forma de marginalidad, desde una mirada lúdica y estilizada, antes que la biografía de un criminal.

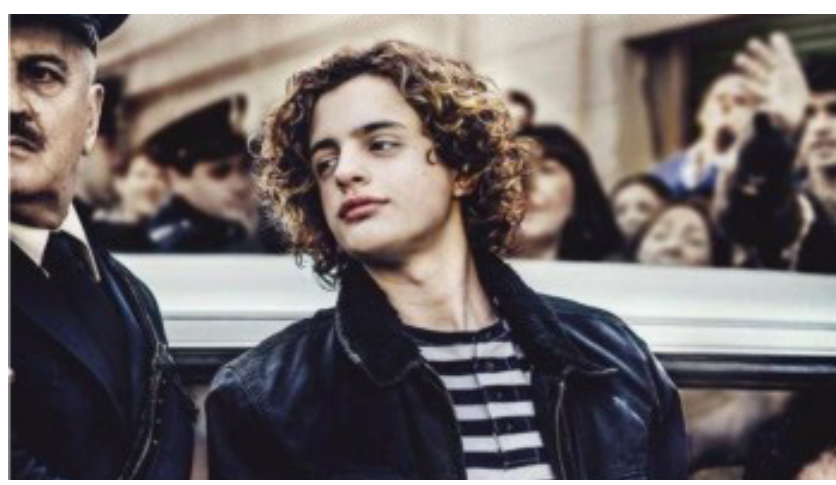

La película de Ortega se presenta como inspirada en la biografía de Robledo Puch, más precisamente en el libro El ángel negro. La feroz vida de Carlos Robledo Puch, del periodista Rodolfo Palacios, publicado por primera vez en 2010 y reeditado en 2018. Como sucede con las adaptaciones -aunque esta no sea, en rigor, una transposición-, el libro fue reeditado en coincidencia con el estreno de la película. La reedición de 2018 tiene en tapa una frase de Luis Ortega en la que este reconoce la influencia del texto sobre el film: "Después de leer el libro quedé fascinado al punto de no tener más remedio que hacer la película”.

El libro de Palacios lleva como portada la fotografía más emblemática de Robledo Puch, tomada el 11 de febrero de 1972, durante una reconstrucción de sus crí- 
menes: se ve al asesino bajando de un auto, escoltado por dos policías, con el pelo enrulado despeinado y la mirada desafiante. La foto del cartel de la película evoca esa imagen, y el vestuario de Carlitos (Lorenzo Ferro) durante el film -casi siempre con remeras rayadas- también remite a aquella imagen icónica del asesino.

Probablemente ese sea el gesto más referencial del film: haber elegido como imagen promocional una que reenvía directamente a la foto más conocida del personaje real. Esa imagen opera de manera indicial antes que icónica: apunta a señalar la proximidad entre el film y su "objeto", activando el pacto de lectura propio de la biopic. Más allá de esa decisión, y de mantener el nombre del protagonista ("Carlitos") y las coordenadas espacio temporales (Buenos Aires, 1971), la trama narrativa se orienta más a la invención que a intentar representar los hechos "tal como sucedieron".

Entre las principales invenciones del film debemos mencionar a los dos secuaces del protagonista: "Ramón Peralta" (Chino Darín) y "Miguel” (Peter Lanzani). Si bien Robledo Puch tuvo dos cómplices -Jorge Ibáñez y Héctor Somoza-, sus nombres y sus biografías difieren de las versiones construidas por la película (salvo por el desenlace de ambos). El film respeta que Robledo y su primer socio se conocieron en la escuela, pero al modificar el nombre introduce un homenaje al padre del director: Jorge Ibáñez pasa a llamarse "Ramón", como Palito Ortega, cuya impronta también es crucial en la banda sonora de la película ${ }^{8}$. El homenaje se hace explícito en una escena en la que este personaje canta "Tengo el corazón contento”, una de las canciones más famosas de Palito, en televisión.

Con respecto a estos dos compañeros también se respeta otro dato crucial de la biografía: que Robledo Puch asesinó a ambos -al primero, en un "accidente" automovilístico que en el film parece provocado por los celos; mientras que al segundo lo mata a balazos y lo quema con un soplete-. Más allá de estos dos crímenes, la narración reduce la cantidad de homicidios cometidos por Robledo Puch. El guion omite dos femicidios y violaciones en los que Robledo fue partícipe, tal vez porque su representación en 2018 solo podría dar lugar a imágenes “intolerables" (Rancière, 2010). Lucrecia Martel había tomado una decisión similar en su adaptación de Zama (2017), donde omitió las escenas de violación y abuso hacia mujeres?.

Además de estas omisiones, la trama realiza otras dos operaciones. Por un lado, condensa: en el asesinato de un sereno se resumen los cuatro homicidios de serenos cometidos por Robledo. Por otro lado, inventa: el anciano de la mansión y el chofer del camión de lácteos son víctimas creadas por el guion, pero no mencionadas en la biografía del asesino ni en su proceso penal.

En términos temporales, el guion establece un recorte claro: se circunscribe a los meses en que Robledo Puch comete los asesinatos. Esta decisión contribuye a separar al personaje de su biografía histórica, y en cierto sentido lo esencializa: Carlitos es sus crímenes, el resto de las circunstancias no importan. A diferencia de otras biopics, que recurren a la infancia del protagonista para encontrar allí la clave de su destino, El ángel no apela a los orígenes para intentar explicar la psicología del personaje. Como plantea Hassler-Forest, con frecuencia las biopics de Hollywood presentan escenas de la infancia del protagonista para "establecer no solo una motivación para la vida posterior y la carrera del personaje, sino también para implicar un sentido de predestinación" $(2013 \text {, p. } 273)^{10}$. En este punto la película también se diferencia de la biografía de Palacios, que se detiene por ejemplo en los maltratos que recibió Robledo de parte de sus compañeros del barrio, o en el vínculo del personaje con sus padres.

\section{El mal como acto de libertad}

Una de las operaciones más significativas que realiza el guion tiene que ver con la presentación de Carlitos como ladrón antes que como asesino. "Todos tenemos un destino. Yo soy ladrón de nacimiento. No creo en esto es tuyo y esto es mío", plantea el protagonista al principio, en un parlamento en off que funciona a modo de auto-presentación del personaje. Aunque la voz en off no vuelve a aparecer luego de esa introducción, la película sigue en todo momento el punto de vista de Robledo Puch.

Al asumir el punto de vista del protagonista, la cámara jamás se ubica en la posición de las víctimas -una decisión que recibió algunas críticas desde el punto de vista ético, pero que, entendemos, debería leerse en el marco de la renuncia del film al realismo documental-. El encuadre no empatiza con los muertos ni se detiene en los cadáveres; la sangre casi siempre queda fuera de campo.

Así como omite toda pre-historia, la película tampoco muestra las consecuencias de las acciones de Robledo: es una historia de crímenes sin castigo, lo que contribuye a la "romantización" del protagonista. La trama sí incluye una breve fuga de la cárcel -la única vez que 
Robledo logró burlar la vigilancia-, ocurrida en 1973, un año después de la primera captura. Sin embargo, ese año de prisión está elidido en la trama: no se muestra la confesión ni la situación del personaje en la cárcel; la película no exhibe la derrota de su protagonista ni explica cómo fue descubierto por la policía. El film termina justo antes de la captura definitiva de Robledo Puch, con una escena de baile que sugiere una apoteosis previa a la caída.

Sin futuro y sin pasado más allá de sus crímenes, Carlitos es presentado como un aventurero cuyas acciones no son juzgadas por el film. Según Simmel, "el aventurero constituye también el ejemplo más recio del hombre ahistórico, de la criatura del presente. Si por una parte no se halla determinado por ningún pasado [...], por otra el futuro no existe para él" (1988, p. 13). Toda biopic se constituye por hibridación con otros géneros: en El ángel, lo biográfico se subordina al film de aventuras. Simmel afirma que la atmósfera de la aventura "es la de un presente incondicional, el desbordamiento del proceso vital en un punto que no tiene ni pasado ni futuro" (p. 23).

Ese presente incondicional define justamente la construcción romántica de Carlitos: un aventurero para quien no hay motivaciones ni fines, sino simplemente el puro acto. En la escena del asalto a la joyería, Carlitos se detiene frente al espejo, juega a probarse unos aros, y le aconseja a Ramón, su cómplice, que disfrute de "estar vivo", en una suerte de carpe diem que subraya la intensidad del presente propia de la aventura: el protagonista experimenta el robo sustancialmente como un acto libre.

A contramano de lo que indicaría el realismo psicológico, el miedo al castigo o a la captura -es decir, el cálculo racional- no incide jamás en las acciones del protagonista. Carlitos es un despreocupado: abandona los autos que roba porque no quiere "hacerse problema"; le regala una alhaja a un linyera. No roba por codicia ni por resentimiento: la película exhibe la pureza del acto, el robo por el robo mismo. No hay causalidad ni racionalidad en la acción, no hay fines: para Carlitos, el crimen es una aventura y por lo tanto se justifica en sí mismo, no es un acto utilitario. El protagonista hace de la transgresión un acto gratuito -y, a la vez, radicalmente egoísta: el otro no es más que un obstáculo-.

En línea con esta configuración de aventurero romántico, Carlitos es presentado como un sujeto libre. Esa libertad es mencionada explícitamente en el comienzo de la película, en un parlamento en off que funciona a modo de introducción: "La gente está loca, ¿̇nadie consi- dera la posibilidad de ser libre?", se pregunta el protagonista, mientras camina por la calle y se cuela en una casa ajena saltando la reja. La libertad del personaje reaparece en las escenas de baile, inmotivadas desde el punto de vista de la construcción diegética, pero funcionales a la caracterización del protagonista.

En El ángel hay dos secuencias de baile, que definen una estructura circular. La primera precede al título de la película, tras una breve introducción; la segunda es la secuencia final, cuando Carlitos baila solo en la casa de los Peralta mientras afuera lo rodea la policía, justo antes de ser capturado y perder, precisamente, la libertad. La circularidad contrasta con la estructura lineal clásica de las biopics, según las describe Landy, para quien las películas del género suelen estar estructuradas de una manera lineal, respetando la cronología de una vida, ya que en una biopic la figura histórica es la fuente de todas las acciones (1991, p. 15).

La libertad aparece asociada también a cierto nomadismo, sintetizado en la canción principal de la película ("Vagando por las calles / mirando la gente pasar..."). La cámara muestra al protagonista caminando por la calle, andando en moto por el barrio o por la ruta, irrumpiendo en casas ajenas: Carlitos puede sumarse a la lista de dromómanos en los que se ha interesado Ortega en sus películas anteriores. Por otra parte, en un diálogo el personaje de "Federica" (William Prociuk) explica que "Carlos" es un nombre de origen germano que significa, justamente, "bombre libre". En otra escena sonará “¿Adónde está la libertad?” de Pappo, en un gesto que invita a leer las transgresiones de Carlitos como actos libres antes que como delitos socialmente penados.

Por último, el film subraya la condición de libertad de su protagonista al asimilar las figuras del criminal y el artista. "El mundo es de los ladrones y de los artistas; el resto tiene que salir a trabajar", dice Ramón en una escena. Carlitos toca el piano, mientras que Ramón baila en televisión e intenta hacer una carrera artística a partir de su vínculo con Federica, el personaje que remite a Federico Klemm. En la casa de Federica, justamente, se fusionan el ámbito del arte y el robo: los protagonistas llevan allí cuadros robados, mientras se celebra una reunión artística presidida por un personaje interpretado por Fernando Noy. Desde una mirada romántica, ambos arquetipos -el del artista y el del criminal- se vinculan con la marginalidad, en tanto suponen la adopción de una forma de vida a contrapelo de las convenciones burguesas. 


\section{Una biopic no realista}

La narración no procura comprender a su protagonista desde un realismo psicológico. En esta línea, la letra de "El extraño de pelo largo", la canción de La Joven Guardia que forma parte central de la banda sonora -abre y cierra el film, sobre las dos escenas en que el protagonista baila-, aporta algunas orientaciones para reconocer la propuesta de la película. La canción no solo resalta el rasgo más prototípico de Carlitos -el pelo rubio, largo y enrulado, que motiva la comparación con Marilyn Monroe-, sino que también ofrece una clave de lectura para la película: "Inútil es que trates de entender / O interpretar quizás sus actos".

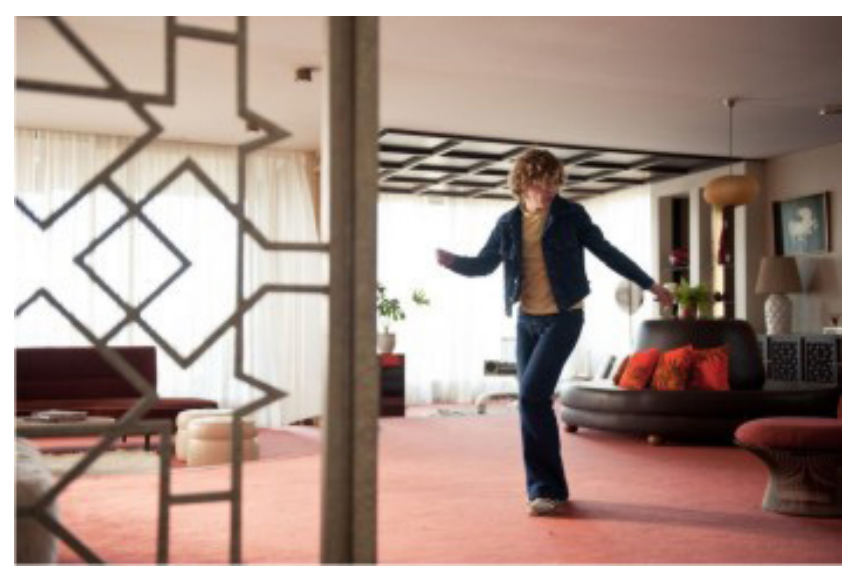

El film renuncia de antemano a todo intento de explicar la conducta de su protagonista: antes que un conocimiento del personaje real, el film ofrece una pregunta sobre la naturaleza del mal y sobre su condición de posibilidad: la libertad. La libertad de Carlitos aparece entonces como el reverso necesario de su maldad. El lazo entre el mal y la libertad fue subrayado, entre otros, por Safranski en un conocido ensayo titulado justamente $E l$ mal o el drama de la libertad. Allí Safranski afirma: "No hace falta recurrir al diablo para entender el mal. El mal pertenece al drama de la libertad humana. Es el precio de la libertad" (2000, p. 13).

Tampoco la familia del personaje aporta elementos para comprender su maldad. Los padres de Carlitos (interpretados por Cecilia Roth y el chileno Luis Gnecco) aparecen como dos personas decentes, trabajadores y cariñosos con su hijo. Sin embargo, el fruto de ese matrimonio decente resulta ser el mayor asesino de la historia argentina. La idea de la cultura del esfuerzo, central en el esquema de esta familia burguesa, queda ridiculizada en la escena en que Carlitos le dice a su padre, en medio de una cena familiar: "Sos mi padre pero yo gano más".
La película exhibe, en todo caso, el fracaso rotundo de la socialización, la ineficacia de la familia para transmitir la moral burguesa.

A contramano de la psicología de la biopic, la trama no despliega las motivaciones del personaje; a contramano de la racionalidad del policial, no detalla las pruebas de los crímenes ni justifica cómo la policía logra descubrir al asesino. Paradójicamente, la "veracidad" del argumento parece eximir al film de la búsqueda de verosimilitud: El ángel cuenta una historia en la que, como reza el lugar común, "la realidad supera a la ficción".

$\mathrm{Si}$ es posible hablar de un "referente", un pre-texto para la película, este no parece ser la biografía de Carlos Robledo Puch, sino más bien su leyenda. La figura real, sus condiciones psicológicas y circunstancias históricas, pierden relevancia frente al peso de sus crímenes en la memoria colectiva: esa memoria no es otra cosa que un relato transmitido a lo largo de los años, una leyenda. En el terreno de lo legendario, plantea Foucault, la distinción entre realidad y ficción se diluye:

Lo legendario, cualquiera que sea su núcleo de realidad, no es nada más, en último término, que la suma de lo que se dice. Es algo indiferente a la existencia o inexistencia de aquel a quien transmite la gloria. Si el héroe existió, la leyenda lo recubre con tantos prodigios, lo enriquece de tantos atributos imposibles que es, o casi es, como si no hubiese vivido. Y si es puramente imaginario, la leyenda transmite acerca de él tantos relatos insistentes que adquiere el espesor histórico propio de alguien que hubiese existido. (1996, p. 126)

Foucault se pregunta qué vidas son dignas de ser contadas: la respuesta no se funda en parámetros morales, sino en la diferencia entre las vidas minúsculas, destinadas a "transcurrir al margen de cualquier discurso" (p. 125), y las vidas excepcionales, entre las que se confunden las de los grandes héroes y los grandes criminales. El terreno donde se mezclan las hazañas y las fechorías, las acciones más admirables y las más crueles, es el de la leyenda. Ese es el sustrato de El ángel, que le permite al guion prescindir de toda preocupación referencial.

Para Foucault, incluso los peores criminales -mejor dicho: sobre todo los peores- gozan de una cierta gloria, análoga a la de los héroes. En ese sentido, Foucault diferencia al criminal del hombre infame: según esa distinción, Robledo Puch no sería un "infame”, dado que, en rigor, "su infamia no es sino una modalidad de la universal fama” (p. 127). En El ángel, la concepción legendaria del protagonista habilita la magnificación de algunas de sus acciones. Carlitos es un ladrón hiperbólico: cuando asalta la armería, se lleva absolutamente todas las armas; 
ha robado tanto dinero que los fajos de billetes forman una montaña sobre la mesa de su casa; hacen falta decenas de policías para detenerlo.

\section{Un ángel caído: violencia y erotismo}

Si bien la película declina todo intento de explicación psicológica, algunos elementos sí remiten a otro rasgo característico de la biopic: la idea de destino. En su estudio pionero, Bingham plantea que "la biopic es un género basado en el destino" (2010, p. 41). Esta noción permite releer la vida del protagonista a partir de un eje único, según el cual el personaje encarna una suerte de arquetipo: en este caso, el arquetipo del criminal, tamizado con el tópico del ángel caído.

El concepto de destino aparece tematizado en la "La casa del sol naciente", la canción que musicaliza el tráiler y una de las escenas más intensas del film, cuando Carlitos prende fuego el auto con el que antes salieron a robar. Se trata de un cover cantado por Palito Ortega, en el que se lamenta un sujeto que ha llegado a un callejón sin salida ("El destino jugó su partida / La partida que yo no elegi"), sin ninguna posibilidad de refugiarse en un hogar o un amor.

En la versión construida por el guion de Ortega, $\mathrm{Pa}-$ lacios y Olguín, al presentarse a sí mismo en la introducción, el protagonista construye una versión pseudo religiosa de su nacimiento: dice que su madre no podía concebir, y que en consecuencia un médico le sugirió que rezara. Luego remata: "Así que acá estoy: un enviado del cielo, un espía de Dios”11.

La metáfora irónica de Carlitos como enviado de Dios remite a la explicación bíblica del origen del mal: allí se presenta al demonio como un ángel caído (Apocalipsis, 12:9); también se afirma la idea de que el mal es seductor y que "Satanás se disfraza como ángel de luz" (2 Corintios, 11:14). En la película, el único personaje que alude al demonio es un loco que aparece sentado en el bar del hotel donde se alojan Carlitos y Ramón: "El enemigo existe”, advierte el loco mirando a Carlitos, como una suerte de profeta ignorado.

La construcción de Carlitos aúna lo angelical y lo demoníaco, la belleza y la maldad, el erotismo y la violencia. Cuando Ramón contrapone a "los ladrones y los artistas" con el resto de la gente que "tiene que salir a trabajar", parece estar citando a Bataille: para este autor, la violencia y el erotismo se oponen al mundo del trabajo. "El trabajo exige un comportamiento en el cual el cálculo del esfuerzo relacionado con la eficacia productiva es constante. El trabajo exige una conducta razonable, en la que no se admiten los impulsos tumultuosos", escribe Bataille (1997, p. 45): esos impulsos son los de la violencia, pero también los del erotismo.

La película juega con esa duplicidad y erotiza la figura del criminal: la cámara se detiene en la mirada -a la vez inocente y perversa- del protagonista; ofrece varios primerísimos primeros planos de los labios de Carlitos. Este es construido como una suerte de efebo, un personaje seductor -y seducido-, un Tadzio malvado. La antítesis de esos labios carnosos queda plasmada en el plano detalle del testículo de José (Daniel Fanego): como en Muerte en Venecia, la juventud se opone a la decrepitud.

En su momento, la prensa sensacionalista asoció la maldad de Robledo Puch con su supuesta homosexualidad. La película retoma esa asociación en clave irónica: subraya constantemente la ambigüedad sexual del personaje, su androginia adolescente. Cuando Ana María (Mercedes Morán) intenta seducirlo, él dice gustar del marido de ella. En el robo a la joyería, Carlitos se pone aros y Ramón le dice que se parece a Marilyn Monroe, mientras que el propio protagonista se compara con Evita. En otras escenas, en cambio, la imagen del personaje remite a la masculinidad rebelde y vulnerable de James Dean.

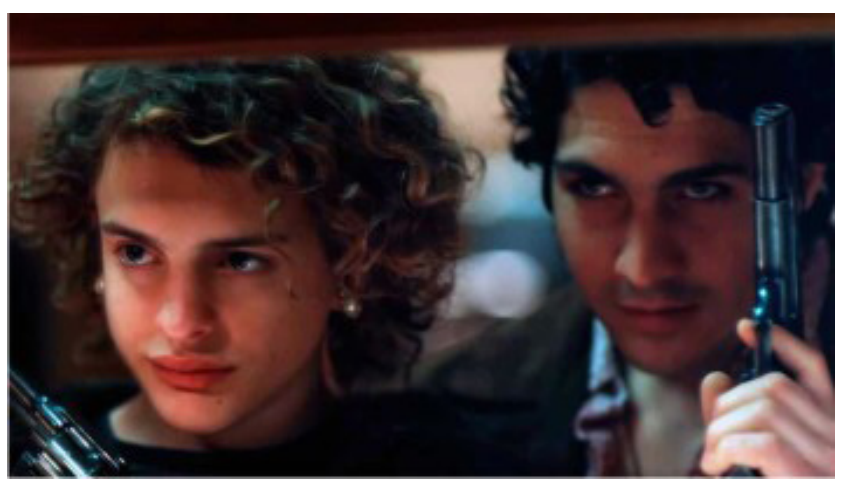

Mientras la violencia resulta procesada por medio de ciertas convenciones del film de aventuras, el erotismo sostiene una trama amorosa que permanece latente, pero que a la vez aporta los únicos elementos explicativos que permiten comprender algunas motivaciones del personaje (por ejemplo, los celos). La relación entre Carlitos y Ramón (Chino Darín) aparece cargada de homoerotismo, en una construcción que remite a la influencia de Jean Genet, una lectura que el propio Ortega mencionó en varias entrevistas (cfr. Basile, 2018).

La trama amorosa es otra invención del guion, así como el clan delictivo de los Peralta no existió en la rea- 
lidad. A su vez, este elemento permite restituir un cierto suspenso, ya que el desenlace de la trama policial -la captura del asesino-es conocido desde el principio por todos los espectadores. En el vínculo entre Ramón y Carlitos la complicidad criminal se superpone con el deseo sexual, un deseo que no se concreta pero define la tensión entre los personajes -y sella el destino del primero-.

El vínculo homoerótico entre dos delincuentes remite a Plata quemada (2000), el film de Marcelo Piñeyro que narraba los crímenes de otra pareja homosexual integrada por el Nene (Leonardo Sbaraglia) y, casualmente, el Ángel (Eduardo Noriega). Tal vez la principal diferencia con Plata quemada es la ausencia de solemnidad y la apelación constante al humor, en buena medida gracias a la simpatía del protagonista, pero también a los guiños del guion.

Por otra parte, la escena en la que Carlitos toca el Himno Nacional en el piano puede leerse en diálogo con otra película argentina protagonizada por un delincuente: $U n$ oso rojo (2002), de Adrián Caetano. En el film de Caetano, una de las obras emblemáticas del Nuevo Cine Argentino, las ideas de crimen y nación aparecen estrechamente asociadas en una escena en la que el Himno Nacional se escucha sobre las imágenes del Oso (Julio Chávez) asesinando a un policía por la espalda durante un asalto.

En otra escena, el padre le pregunta a Carlitos de dónde saca la plata y él le responde: "De donde la saca todo el mundo". Este intercambio también evoca una secuencia de Un oso rojo en la que el Oso sostenía que "toda la guita es afanada". Pero si en el film de Caetano esa afirmación parecía suponer una declaración de principios, en el de Ortega resulta cargada de humor: Carlitos insiste, irónicamente, en que su oficio de ladrón "también es un trabajo". En Caetano estos gestos admitían -y reclamaban- una lectura política, mientras que en Ortega parecen ser tan gratuitos como los crímenes de Carlitos.

\section{Los setenta en clave retro}

En El ángel, la presentación del contexto histórico está trabajada a partir de una estética pop, que apela a la música, el vestuario y la utilería para construir una imagen retro de los setenta. La referencia más explícita aparece al principio, cuando una leyenda ubica la trama en espacio y tiempo: “Buenos Aires, 1971”. Luego, hacia el final, se escucha de fondo un mensaje radiofónico del dictador Alejandro Agustín Lanusse, que presidió la Argentina entre 1971 y 1973.
También hay una mención al contexto político cuando Carlitos y Ramón son detenidos por no llevar documentos, y el comisario les pregunta si son guerrilleros. "No nos interesa la política", responde Ramón, en una declaración que podría referirse tanto a los personajes como a la película. Carlitos agrega enseguida: "Yo quiero estudiar para ser policía”, desplazando la escena hacia el humor e impidiendo que la referencia a la guerrilla se cristalice en una reflexión histórica de mayor espesor.

La construcción temporal aparece más permeada por la nostalgia que por la memoria: el film no pretende aportar a la comprensión histórica de los años 70 -probablemente, la década más transitada por el cine argentino-. Jameson (2002) plantea que el film nostálgico renuncia a la posibilidad de representar el pasado: este queda entonces reducido a una serie de estereotipos, y pierde su espesor histórico.

Según posiciones como la de Jameson, esa es la principal diferencia entre nostalgia y memoria: la ausencia, en la primera, de un "sentido de la historia" (2002, p. 37). De todos modos, esa ausencia no debería leerse necesariamente como una falta. A diferencia de la memoria, la nostalgia suele aparecer cargada de una connotación negativa en el discurso intelectual, en un gesto que parece admitir un único modo de representación del pasado. Sin embargo, la decisión de condensar el pasado en una serie de referencias -visuales, musicales, estéticas-, sin mayores ambiciones explicativas, resulta coherente con la propuesta de un film que renuncia desde el principio al realismo documental, al biografismo y a la Historia.

Antes planteamos que El ángel señala el fracaso de la socialización: es la historia de un criminal que nace en una familia decente, un protagonista cuyos crímenes no tienen genealogía ni pueden explicarse a partir de su entorno. Sin embargo, para un pensador como Gabriel Tarde, el criminal no es aquel en quien falló la socialización, sino un sujeto sobre-socializado: "Ni déficit de socialización, ni eclosión de instintos antisociales y solipsistas: en nadie la sociedad está tan presente como en aquellos que se oponen violentamente a ella. Una especie de sobre-socialización trabaja al delincuente que inventa”, postula Tonkonoff (2008, p. 44).

Esa lectura invita a reintroducir cierta dimensión histórica en el film. La hipótesis de Tarde permite leer la figura de Robledo Puch no como un anómico, un extraño a la sociedad de su época -la Argentina de los setenta-, sino al contrario: como la máxima expresión, el paroxismo de esa sociedad atravesada crecientemente por la violencia y la represión. En El ángel, Carlitos es ante 
todo un romántico, un rebelde sin causa, un ángel negro. Sin embargo, también podemos verlo como el emergente de una situación social que avanzaba, irremediablemente, hacia un desprecio por la vida humana que se tradujo en un derramamiento de sangre sin precedentes en la historia nacional del siglo XX.

\section{Conclusiones}

En El ángel, la biografía de Carlos Robledo Puch se ve reducida a su mínima expresión: es apenas una excusa para narrar una historia que rodea el problema del mal y la libertad, la belleza y la perversión, la violencia y el erotismo como contracaras de la vida normal, de la existencia gris de las mayorías sociales que permanecen anónimas, in-fames. El guion de Ortega, Palacios y Olguín toma el nombre propio y algunas circunstancias históricas para darle concreción a una figura formada más bien de la sustancia de lo mítico.

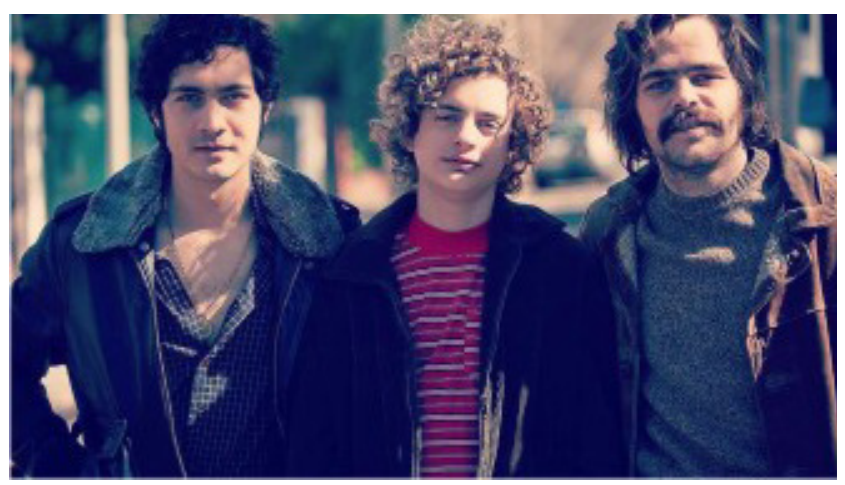

La trama adelgaza la información, y se detiene en cambio en escenas gratuitas, con un valor más simbólico que na- rrativo: Carlitos colocando las joyas robadas sobre los genitales de Ramón; Carlitos tocando el himno nacional en el piano; Ramón cantando "Tengo el corazón contento" en televisión; Fernando Noy recitando un poema en la casa de Federica. Esa irrupción de secuencias que no hacen avanzar la trama, que podrían faltar o estar ubicadas en cualquier otro punto de la narración, permite trazar una analogía con el modo de actuar del protagonista: sus crímenes también son actos gratuitos, desprovistos de motivaciones y de explicaciones racionales.

De esta manera, el film da lugar a cierta identificación entre la figura del director y el personaje principal: la vida de Carlitos, como la narración misma, se presenta como una sucesión de actos libres. La película parece reclamar para sí misma aquello que afirma la canción de la Joven Guardia, y que vale también para Carlitos: "Inútil es que trates de entender / O interpretar quizás sus actos". La figura del criminal queda asimilada con la del artista, en línea con lo que dice explícitamente Ramón en la película.

Esa asimilación entre artista y criminal se funda en la marginalidad de ambos, en la oposición entre historia singular y maquinaria social. El hilo conductor de la trama tiene que ver con esa interrogación acerca de los márgenes como zona de libertad individual; la aventura se impone sobre el crimen y la trama amorosa predomina sobre la trama policial. En otras palabras, El ángel no supone un espectador ávido de conocimiento histórico. A diferencia de otras biopics, no apuesta a borrar las fronteras entre realidad y ficción, sino que se afirma claramente en el terreno de la invención, para preguntarse (y preguntarnos) qué es lo que nos atrae tanto de estos monstruos sociales que, en la misma medida en que nos espantan, nos someten a una inquietante seducción.

\section{Referencias}

Arfuch, L. (2002). El espacio biográfico. Dilemas de la subjetividad contemporánea. Fondo de Cultura Económica.

Basile, E. (2018, 5 de agosto). “Luis Ortega: 'Queríamos echar luz sobre esa parte descontrolada de la infancia que busca límites, que es distinto a hacer el mal”". Escribiendo Cine. http://www.escribiendocine.com/entrevista/0015078-luis-ortega-queriamos-echarluz-sobre-esa-parte-descontrolada-de-la-infancia-que-busca-limites-que-es-distinto-a-hacer-el-mal/

Bataille, G. (1997). El erotismo. Tusquets.

Bingham, D. (2010). Whose lives are they anyway? The biopic as contemporary film genre. Rutgers University Press.

Carabajal, G. (2008, 29 de junio). “Nunca asesiné a nadie’, asegura Robledo Puch”. La Nación. https://www.lanacion.com. ar/1025783-nunca-asesine-a-nadie-asegura-robledo-puch

Cines Argentinos (2018, 7 de agosto). “El ángel logra el récord de cantidad de salas para el cine argentino”. https://www.cinesargentinos.com.ar/noticia/5711-el-angel-logra-el-record-de-cantidad-de-salas-para-el-cine-argentino/

Custen, G. (1992). Bio/pics: How Hollywood Constructed Public History. Rutgers University Press.

Ducrot, O.; Todorov, T. (1995). Diccionario enciclopédico de las ciencias del lenguaje. Siglo XXI.

Foucault, M. (1996). La vida de los hombres infames. Altamira. 
Genette, G. (1989). Palimpsestos. La literatura en segundo grado. Taurus.

Hassler-Forest, D. (2013). “American Splendor: Narrative and Biography between Media”. Passepartout, vol. 18, № 34, pp. $263-281$. Jameson, F. (2002). El giro cultural. Escritos seleccionados sobre el posmodernismo 1983-1998. Manantial.

Landy, M. (1991). British Genres: Cinema and Society, 1930-1960. Princeton University Press.

Lavabre, M.C. (2007). "Maurice Halbwachs y la sociología de la memoria”. En Pérotin-Dumon, Anne (dir.). Historizar el pasado vivo en América Latina. http://etica.uahurtado.cl/historizarelpasadovivo/es contenido.php

Mazzini, M. (2017, 27 de septiembre). “Lucrecia Martel: 'No puedo avalar con mi película las fantasías violatorias'”. Brando. https:// www.lanacion.com.ar/2066908-lucrecia-martel-no-puedo-avalar-con-mi-pelicula-las-fantasias-violatorias

Moulin, J. (2016). "Biophoty: The Biofilm in Biography Theory". Revue LISA/LISA e-journal, vol. XIV, N². https://doi. org/10.4000/lisa.8959

Ortega, L. (2018). “Hay que matar hasta a los amigos”, prólogo a Palacios, Rodolfo: El ángel negro. La feroz vida de Carlos Robledo Puch. Sudamericana.

Palacios, R. (2018). El ángel negro. La feroz vida de Carlos Robledo Puch. Sudamericana.

Prividera, N. (2018, 21 de agosto). "Un muchacho como yo. A propósito de El ángel”. Con los ojos abiertos. www.conlosojosabiertos.com/inconformista-02-la-colulmna-nicolas-prividera-muchacho-proposito-angel/

Rancière, J. (2010). “La imagen intolerable”. En El espectador emancipado. Manantial.

Renders, H.; De Haan, B.; Harmsma, J. (eds.) (2017). The Biographical Turn: Lives in History. Routledge.

Robinson, M. (2016). Mapping the British biopic: Evolution, Conventions, Reception and Masculinities [tesis doctoral, University of the West of England]. http://eprints.uwe.ac.uk/29205

Rosenstone, R. (2006). History on Film/Film on History. Pearson Longman.

Safranski, R. (2000). El mal o el drama de la libertad. Tusquets.

Sarlo, B. (2005). Tiempo pasado. Cultura de la memoria y giro subjetivo. Siglo XXI.

Simmel, G. (1988). Sobre la aventura. Ensayos filosóficos. Península.

Tonkonoff, S. (2008). "La sociología criminal de Gabriel Tarde”. Delito y Sociedad. Revista de Ciencias Sociales, № 26, pp. 3757. https://doi.org/10.14409/dys.v2i26.5295

White, H. (1992). El contenido de la forma. Narrativa, discurso y representación histórica. Paidós.

\section{Referencias filmográficas}

Caetano, I. A. (2002). Un oso rojo [película]. Lita Stantic Producciones.

Ledo, R. (1995). Sin condena [serie de televisión]. Canal 9.

Martel, L. (2017). Zama [película]. Rei Cine, El Deseo, Canana Films, KNM, Bananeira Filmes, Louverture Films, Netherland Filmfund, INCAA.

Ortega, L. (2018). El ángel [película]. K\&S Films, Underground Contenidos, El Deseo, Telefe, INCAA.

Piñeyro, M. (2000). Plata quemada [película]. K\&S Films, Cuatro Cabezas, Tornasol Films, Mandarina Films, Taxi Films.

\footnotetext{
1 “Me inventaron porque no había un Charles Manson criollo", dijo desde la cárcel en una entrevista en la que negó todos sus crímenes (Carabajal, 2008).

2 "Film may lack the ability to provide deep psychological insight, or extensive descriptions of particular intellectual or political milieus, but it can suggest with a terrifying immediacy how the past looked, and how people moved, felt, spoke and acted in time. Unlike the written word, the biofilm, even in its flashbacks always functions in the present tense, suggesting, even making you feel as if you have lived through those moments yourself."

3 "This characteristic aspect of biophoty exerts a most interesting influence on modern biography, liberating it from the largely self-imposed obligation of telling a life from the cradle to the grave”.

$4 \quad$ Siguiendo a Ricoeur, White define la tarea de entramado (en inglés, emplotment) de la siguiente manera: "El significado de los relatos está en su entramado. Mediante el entramado, una secuencia de acontecimientos se 'configura' ('se capta conjuntamente') a fin de representar simbólicamente lo que de otro modo sería inexpresable en el lenguaje” (1992, p. 182). En otras palabras, el entramado es una operación de mediación simbólica que establece la "aprehensión conjunta” de acontecimientos dispersos.

5 "The majority of biopics employ strategies and conventionalised techniques in order to persuade an audience that the depiction is "factual"'.
} 
6 Del libro surge que hasta el propio Robledo Puch era consciente del potencial cinematográfico de su historia: "Su plan era seducir a Francis Ford Coppola, Quentin Tarantino o Martin Scorsese para que filmaran su historia. Robledo quería ser interpretado por Leonardo Di Caprio y se postulaba como doble de riesgo y guionista" (Palacios, 2018, p. 35).

7 Peirce plantea que el índice es un tipo de signo que mantiene una relación de contigüidad con el objeto (a diferencia del ícono, definido por la semejanza, y el símbolo, que implica un lazo convencional). El autor define el índice como "un signo determinado por su objeto dinámico [es decir, el objeto tal como es] en virtud de la relación real que mantiene con él” (cit. en Ducrot y Todorov, 1995, p. 105).

8 La lectura de Prividera (2018) señala incluso algunas líneas de continuidad entre la obra cinematográfica de Palito Ortega en la década de 1970 y la película de su hijo, por ejemplo a partir del personaje de Ramón y su deseo de triunfar como artista.

9 "Si vivís en un país en el que cada día matan a una mujer y filmás una escena de violencia contra una mujer, aunque puedas dar muchos matices sobre las circunstancias, es intolerable [...] No podemos avalar con discursos públicos escenas que abonan la fantasía violatoria de los hombres", declaró Martel en una entrevista (Mazzini, 2017).

10 «[I]n the Hollywood biopic genre, [...] scenes from the main character's childhood commonly establish not only a motivation for the character's later life and career, but also imply a sense of predestination, assigning unique qualities to the character that have clearly remained consistent throughout the subject's life".

11 Esa versión “religiosa” de la concepción de Robledo Puch también aparecía en el libro de Palacios: “[Víctor y Aída] buscaron ser padres durante dos años, pero los intentos fracasaron. Eso los hizo pensar que no podían tener hijos. Aída rezó con fervor en la parroquia San Isidro Labrador, donde se había casado. Siempre creyó que esas plegarias dieron más resultados que el tratamiento que le había dado su médico" (Palacios, 2018, p. 48). 